\title{
Editorial
}

\section{Welcome home}

With this issue an era in the history of Acta Neuropsychiatrica comes to its end. From 1 January 2013, the responsibility and ownership of the content in Acta Neuropsychiatrica will be fully transferred to the hands of Scandinavian College of Neuropsychopharmacology (SCNP). Acta Neuropsychiatrica, owned by John Wiley \& Sons, became the official Journal of $S C N P$ in 2011 (1), and with the new step effective 1 January 2013, the partnership between the Journal and the Scientific College will be fully implemented. Both the SCNP and the Editors are excited about this development, which we believe will help further strengthen the Journal, and pave room for new initiatives.

Indeed, during the past decade, Acta Neuropsychiatrica has been through a fascinating and impressive development. A brief search in the archives reveals several high impact papers, a visionary transition to full online journal, and several new concept papers all positively received. Today, the Journal receives submissions from all over the globe, far more than can be published. With the linkage to a Scientific College, the Journal has returned 'back to its societal origin', as it began in 1989 as the official Journal of the society, IGBP (Interdisciplinair Genootschap voor Biologische Psychiatrie).

None of this development, however, would have been possible without the valuable support and contribution from John Wiley \& Sons. A special acknowledgement must be devoted to Lisbeth Bruun Cranfield from John Wiley \& Sons in Copenhagen. Without the enthusiasm, spirit and energy you have devoted to Acta Neuropsychiatrica during the years, we would not be where we are today. Fortunately, I am certain that $S C N P$ will continue to stimulate and contribute to the well-being of the Journal as John Wiley \& Sons have done. The integration of Acta Neuropsychiatrica within the scientific activities of $S C N P$ represents a major milestone in the more than 50 year history of the college.

Now one could think that Acta Neurosychiatrica will be exclusive to Scandinavian agendas. This is not the case. Acta Neuropsychiatrica will remain fully independent and operational from the $S C N P$, and as clearly reflected by the editorial board, the ambitions of the Journal are much more than Scandinavian alone, as clearly illustrated by the present issue, with contributions from Taiwan, Switzerland, Italy, Japan, India and Korea.

On behalf of the editorial board, I hope you will enjoy reading this issue. I also wish to thank all reviewers and contributors for a very successful 2012 and a Happy New Year, 2013.

Gregers Wegener

Editor-in-Chief, Acta Neuropsychiatrica; and Aarhus University, Aarhus, Denmark

\section{Reference}

1. Wegener G, Andreassen OA. Acta Neuropsychiatrica and Scandinavian College of Neuropsychopharmacology (SCNP). Acta Neuropsychiatr 2011;23:199-200. 